March - 2007

\title{
The Current Status and Future Prospects of Corporate e-Learning in Korea
}

\author{
Cheolil Lim \\ Seoul National University of Korea
}

\begin{abstract}
Corporate e-Learning in Korea has grown rapidly over the previous six years (2000-2005). This study argues that the main cause of this heightened interest in corporate e-Learning in Korea was not that companies needed to provide high-quality training programs through the Internet, but rather that the government took initiative to transform the state into an information-based society. The policies for quantitative growth with minimum levels of quality and uniformity have been dominant and have resulted in the lack of diverse e-Learning types for authentic practices in workplaces. This paper suggests that in order to cope with the new competency requirements of employees, corporate e-Learning should be guided both by governmental support and by company initiative.
\end{abstract}

Keywords: Corporate e-Learning; Korea

\section{Introduction}

Open and distance learning in Korea had not been fully implemented and discussed prior to 2000 . Until then, and since 1972, systematic formal education for adult learners who did not have the opportunities to enter more traditional colleges had only been provided at such a mega university as the Korean National Open University (KNOU). Traditional, face-to-face education had been the dominant mode of teaching, while distance learning made up only a small portion of the Korean educational system. However, nine cyber universities, which were established in 2001, and the new Internet correspondence training policy for corporate e-Learning by the Ministry of Labor in 1999, initiated profound changes in the Korean educational system (Lim, 2003). Today, many Korean adult learners can pursue education through the various distance learning technologies. Online college courses are delivered via printed material, radio, television, MP3, portable multimedia players (PMP), and the Internet. Also, at present, distance corporate training programs are delivered by mail and online as e-Learning.

The unprecedented growth of corporate e-Learning in Korea has been a major feature of distance learning since 2000. The Korean Ministry of Labor reported that the growth rate of Internet correspondence training participants was 6,281 percent over the past six years $(19,653$ in 1999 and 1,254,066 in 2005) (Ministry of Commerce, Industry and Energy, Korea Institute for Electronic Commerce, \& Korea Association of Convergence Education, 2006). While this astronomical figure can be explained in many ways (Lee, 2006) with positive results, its negative effects on corporate e-Learning and distance learning have also been noted. 
This study intends to discuss the causes and effects of the rapid growth, as well as explore directions for future research and practice with regard to corporate e-Learning in Korea. To determine the current issues, the study focuses on the significant developments implemented by a government-funded research center, the Korean Research Institute for Vocational Education \& Training (KRIVET), over the past six years (2000-2005). KRIVET's impact on the development of corporate e-Learning can hardly be overstated (Lee, 2006). The causes of those developments and various resulting problems are examined in this paper. Finally, based upon this analysis, future directions are suggested.

\section{Current Developments in Corporate e-Learning in Korea: 2000 2005}

Corporate e-Learning in Korea developed in earnest following the implementation of a new government policy in 1999 on Internet correspondence training. Since then, the development of the field can be measured in five ways: rapid quantitative growth, government initiatives, dominance of the tutorial mode, quality assurance, and high adoption rates among large corporations. These will be discussed in turn.

\section{Rapid quantitative growth}

One of the salient features of corporate e-Learning in Korea over the past years has been its rapid quantitative growth. In Table 1, it may be observed that the number of employees who participated in the Internet correspondence training program or e-Learning greatly increased from 19,653 in 1999 to $1,254,066$ in 2005 (approximately 63.8 times more). In 1999, only 2.5 percent of the total number of trainees participated in Internet correspondence training. But in 2005, that ratio increased up to nearly half of the total number of trainees, to 46.4 percent, in 2005.

Table 1. Number of Trainees Supported by Employment Insurance Act (1999-2005)

\begin{tabular}{|c|c|c|c|c|c|c|c|c|c|}
\hline \multirow[t]{2}{*}{ Year } & \multicolumn{2}{|c|}{ Internet-Based } & \multicolumn{2}{|c|}{ Postal-Based } & \multicolumn{2}{|c|}{ Classroom-Based } & \multicolumn{2}{|c|}{ Total } & \multirow{2}{*}{$\begin{array}{c}\text { Internet } \\
\text { Training } \\
\text { Rate } \\
\left(\mathrm{A} / \mathrm{B}^{*} 100\right)\end{array}$} \\
\hline & $\begin{array}{l}\text { Trainees } \\
\text { (A) }\end{array}$ & $\begin{array}{c}\text { Increase } \\
\text { rate }\end{array}$ & Trainees & $\begin{array}{l}\text { Increase } \\
\text { rate }\end{array}$ & Trainees & $\begin{array}{c}\text { Increase } \\
\text { rate }\end{array}$ & $\begin{array}{l}\text { Trainees } \\
\text { (B) }\end{array}$ & $\begin{array}{c}\text { Increase } \\
\text { rate }\end{array}$ & \\
\hline 1999 & 19,653 & - & 85,055 & - & 676,700 & - & 781,408 & - & $2.5 \%$ \\
\hline 2000 & 137,712 & $600.7 \%$ & 161,825 & $90.3 \%$ & 920,797 & $36.1 \%$ & $1,220,334$ & 562 & $11.3 \%$ \\
\hline 2001 & 406,159 & $1949 \%$ & 199,242 & $23.1 \%$ & 950,001 & $32 \%$ & $1,555,402$ & 27.5 & $26.1 \%$ \\
\hline 2002 & 543,320 & $33.8 \%$ & 197,045 & $-1.1 \%$ & 843,958 & $-11 . \% 2$ & $1,584,823$ & 19 & $34.3 \%$ \\
\hline 2003 & 629,930 & $159 \%$ & 193,570 & $-1.8 \%$ & 838,478 & $0.7 \%$ & $1,661,978$ & 49 & $37.9 \%$ \\
\hline 2004 & 929,771 & $47.6 \%$ & 283,338 & $46.4 \%$ & 790,354 & $-5.7 \%$ & $2,003,463$ & 20.6 & $46.4 \%$ \\
\hline $\begin{array}{c}2005 \\
*\end{array}$ & $1,254,066$ & $349 \%$ & 339,645 & $199 \%$ & $1,171,630$ & $48.2 \%$ & $2,705,341$ & 35.0 & $46.4 \%$ \\
\hline
\end{tabular}

This high growth was due to the expansion of the Employment Insurance Act, which earmarked financial support for e-Learning programs. This legislation allowed the Ministry of Labor to 
begin in 1999 providing institutional support. Thus, the number of corporations and workers that participated in e-Learning increased rapidly over the previous 5-6 years. Moreover, corporations took advantage of e-Learning, giving more employees access to educational opportunities at relatively low cost. Large corporations quickly adopted the e-Learning systems and invested money to develop programs.

The rapid growth of corporate e-Learning in Korea can also be attributed to an increase in theoretical studies on corporate e-Learning. One of the leading journals on corporate training in Korea is the Journal of Corporate Education. This academic journal published its first volume in 1998 in the area of training methods, focusing especially on the applications of different technologies and programs. Not surprisingly, the journal has discussed e-Learning with regular frequency since 1999. Of the 13 volumes of the journal, 26 of 79 articles (33\%) have dealt directly with the subject of corporate e-Learning. Considering the plethora of educational methods and issues in corporate training that could be discussed, devoting over 30 percent of the journal articles to e-Learning is doubtlessly a testament to the rapid quantitative growth of the field, as well as the high level of theoretical interest it has garnered in Korea.

\section{Government initiatives on corporate e-Learning}

The Korean Government, especially the Ministry of Labor, has played a significant role in developing the field of corporate e-Learning. In accordance with the government's strategic plan hatched in the mid-1990s to transform the country into a knowledge-based information society, the Ministry of Labor has been the primary driving force behind the implementation of eLearning for corporate training since 1998. That year the Ministry of Labor initiated a pilot project that tested e-Learning based training courses, a project that led to the conclusion that correspondence training should include both Internet correspondence training and postal correspondence training, and which resulted in expansions the following year. This decision caused both corporate e-Learning and distance learning for adults to grow rapidly in Korea in 2000 (see Table 1). Furthermore, as alluded to previously, the Ministry of Labor established a special division, the e-Learning Center at KRIVET, to monitor the quality standards of the eLearning institutes and of the Internet correspondence training program, as well as to establish a new support system and make recommendations.

In addition to these early initiatives of the Ministry of Labor, subsequent measures and policies have also been implemented since 2000 to boost corporate e-Learning (Lee, 2006). In order to support corporate e-Learning on a long-term basis, the Ministry of Labor and the e-Learning Center at KRIVET developed the Corporate e-Learning Mid-Period Development Plan, 20042008, which proposed strategies covering various aspects of e-Learning such as servicing and maintenance of the system, infrastructure construction, cultivation of human resources, standardization, and quality control. Recently, Internet correspondence training regulations have also been revised to incorporate 'blended learning' and a scaled training fee structure, based on an analysis of the quality of the e-Learning institutes. Lastly, the worker's tuition support system has been modified as well so that individual workers can receive financial support when they register independently for e-Learning programs.

\section{Dominance of tutorial e-Learning}

Most corporate e-Learning courses in Korea are in tutorial format in which major points are supplemented with elaborations and examples ('Intro' and 'Lesson' in Figure 1) followed by practice problems ('Activity' in Figure 1). Various design strategies have been applied - for 
example, Keller's ARCS (Attention, Relevance, Confidence, Satisfaction) model has been adopted to enhance effectiveness and for animated presentations advanced technologies, such as Flash, have become standard authoring tools.

Figure 1. An Example of e-Learning: Tutorial type

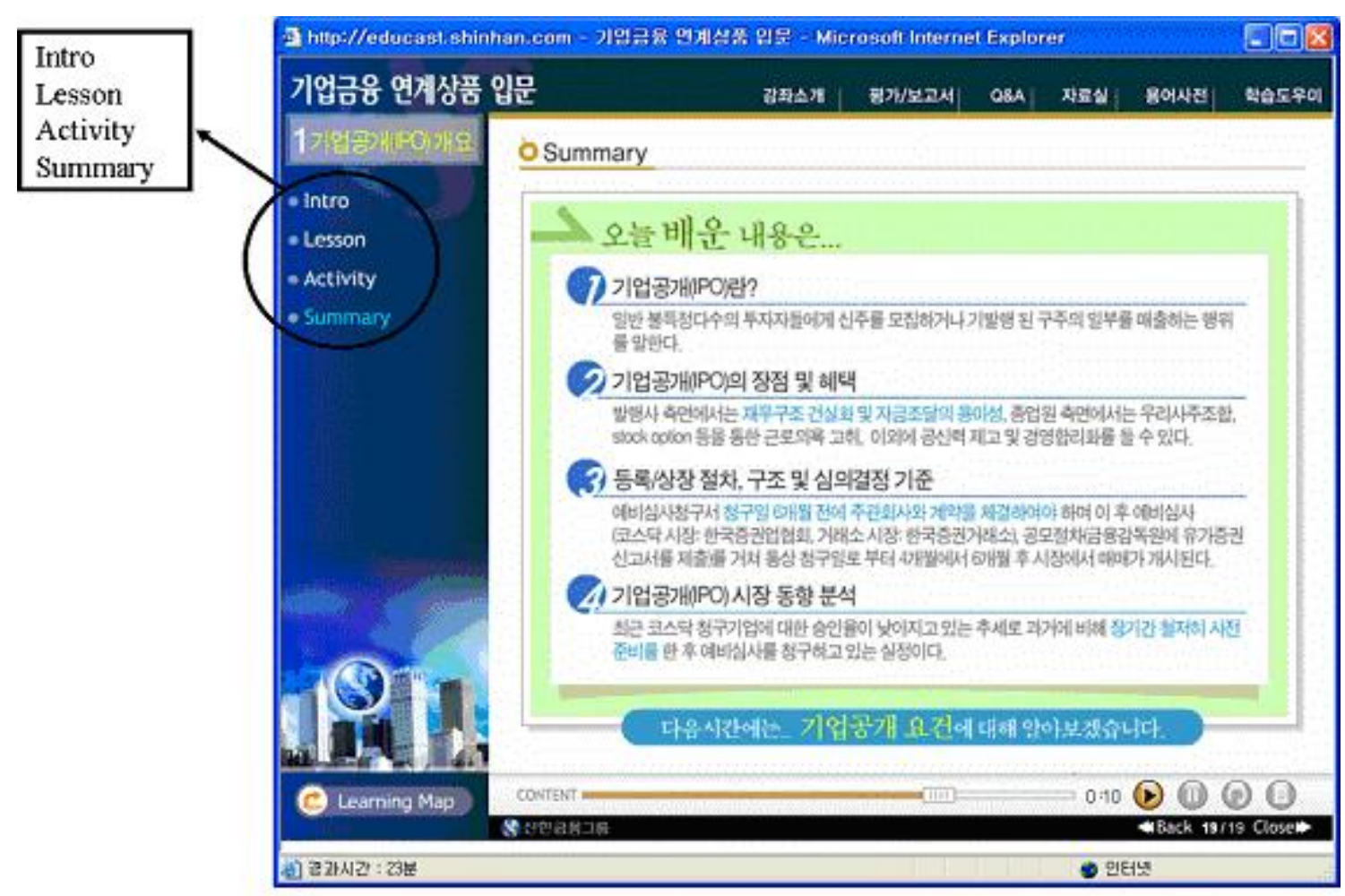

Table 2 shows that nearly 90 percent of all e-Learning content in 2005 were tutorials in either HTML or Lecture-on-Demand (LOD) format. The remaining 10 percent were simulations that honed technical skills. As these two types - tutorials and simulations - became so ubiquitous over the past three years in the field of corporate e-Learning, the government's Employment Insurance Fund eventually dropped support for other types of e-Learning programs.

Table 2. e-Learning Program Proportion by Types from 2003 to 2005

\begin{tabular}{|c|c|c|c|c|c|c|c|}
\hline \multicolumn{2}{|c|}{ Types } & \multicolumn{2}{|c|}{2003} & \multicolumn{2}{|c|}{2004} & \multicolumn{2}{|c|}{2005} \\
\hline \multirow{3}{*}{ Tutorial } & & Self developing & Outsourcing & $\begin{array}{c}\text { Self } \\
\text { developing }\end{array}$ & Outsourcing & $\begin{array}{c}\text { Self } \\
\text { developing }\end{array}$ & Outsourcing \\
\hline & HTML & $545(88.0)$ & $1,086(79.3)$ & $738(88.0)$ & $1,005(68.6)$ & $742(79.7)$ & $1,082(80.8)$ \\
\hline & LOD & $26(4.2)$ & $212(15.5)$ & $33(3.9)$ & $315(21.5)$ & $83(8.9)$ & $138(10.3)$ \\
\hline \multicolumn{2}{|c|}{ Simulation } & $48(7.8)$ & $72(5.3)$ & $68(8.1)$ & $146(10.0)$ & $106(11.4)$ & $119(8.9)$ \\
\hline \multicolumn{2}{|c|}{ Total } & $\begin{array}{c}619 \\
(100.0 \%)\end{array}$ & $\begin{array}{c}1,370 \\
(100.0 \%)\end{array}$ & $\begin{array}{c}839 \\
(100.0 \%)\end{array}$ & $\begin{array}{c}1,466 \\
(100.0 \%)\end{array}$ & $\begin{array}{c}931 \\
(100.0 \%)\end{array}$ & $\begin{array}{c}1,339 \\
(100.0 \%)\end{array}$ \\
\hline
\end{tabular}

Source: Lee, S. et al. (2006). Evaluation of Internet Correspondence Training Institutes, Year 2005. Seoul: KRIVET 


\section{Quality assurance}

The Korean Government, and the Ministry of Labor in particular, has tried to assure e-Learning quality over the previous years. In 2002, the e-Learning Center at KRIVET launched an assessment system to judge the appropriateness of Internet correspondence training programs. All e-Learning programs supported by the Employment Insurance Fund were required to be evaluated by the Center. As seen in Figure 2, the B level grew annually from 16.5 percent in 2002 to 48.1 percent in 2005, demonstrating that instructional design and content quality were, indeed, improved. Conversely, the proportion of D and F level steadily decreased from 27.5 percent in 2002 to 5 percent in 2005 . The quality of the e-Learning programs was successfully improved by implementing the assessment system.

Figure 2. e-Learning Program Assessment Results (2002-2005)

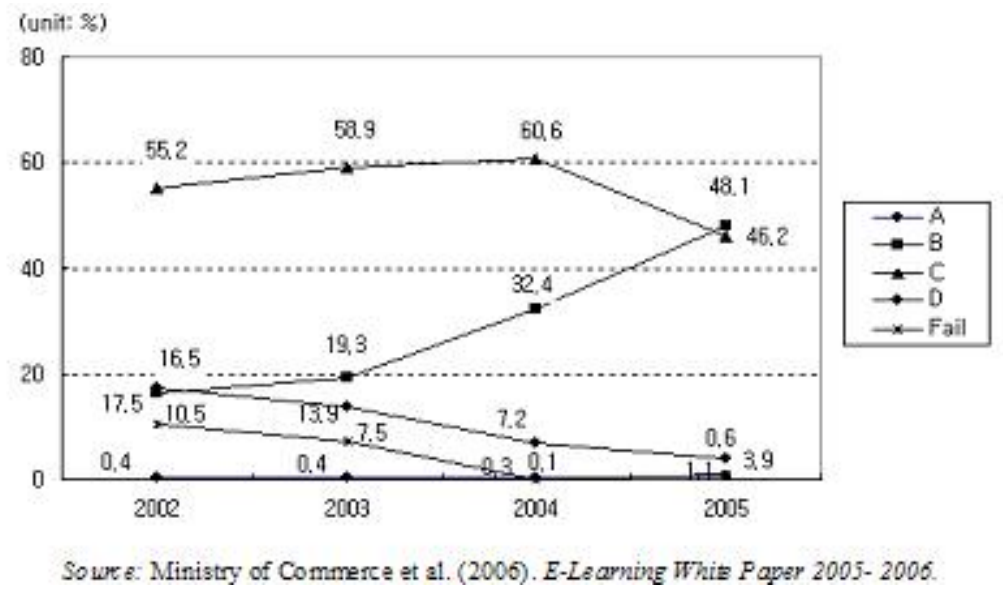

\section{High adoption rate in large companies}

Participation in corporate e-Learning programs was not been evenly distributed across the corporate sector. Employees of larger corporations comprise the largest proportion of Internet correspondence training system participants. Table 3 shows that in 2004, just 8 percent of training participants from assembly lines in small and medium companies participated in Internet correspondence training programs, while nearly 30 percent of those from large companies did so.

Table 3. The Proportion of Training Types for Assembly Line Workers by Company Size

\begin{tabular}{|c|c|c|c|c|c|c|c|c|c|c|c|c|}
\hline \multirow{3}{*}{$\begin{array}{l}\text { Company } \\
\text { Size }\end{array}$} & \multirow{2}{*}{\multicolumn{2}{|c|}{$\begin{array}{l}\text { Classrom } \\
\text { Traiming }\end{array}$}} & \multirow{2}{*}{\multicolumn{2}{|c|}{$\begin{array}{l}\text { Internet } \\
\text { Training }\end{array}$}} & \multirow{2}{*}{\multicolumn{2}{|c|}{$\begin{array}{l}\text { Postal } \\
\text { Traming }\end{array}$}} & \multicolumn{4}{|c|}{ (Unit: number, person) } & \multirow{2}{*}{\multicolumn{2}{|c|}{ Total }} \\
\hline & & & & & & & $\begin{array}{r}\text { Small\& } \\
\text { Com } \\
\text { Conso }\end{array}$ & $\begin{array}{l}\text { Medium } \\
\text { pany } \\
\text { rtimm }\end{array}$ & Field tr & aining & & \\
\hline & Prograns & Trainees & Programs & Traines & Programs & Trainees & Program 5 & Trainess & Programs & Trainees & Programs & Trainees \\
\hline $\begin{array}{l}\text { Small } \\
\text { and } \\
\text { Medium }\end{array}$ & $\begin{array}{c}1,847 \\
(71.3 \%)\end{array}$ & $\begin{array}{c}14,432 \\
(63.27 \%)\end{array}$ & $\begin{array}{c}432 \\
(16.8 \%)\end{array}$ & $\begin{array}{c}1.877 \\
(8.2 \%)\end{array}$ & $\begin{array}{c}300 \\
(11.6 \%\end{array}$ & $\begin{array}{r}6386 \\
(28 \%)\end{array}$ & $\begin{array}{c}3 \\
(0.1 \%)\end{array}$ & $\begin{array}{c}22 \\
(0.1 \%)\end{array}$ & $\stackrel{8}{8}$ & $\begin{array}{c}90 \\
(0.4 \%)\end{array}$ & 2,590 & 22807 \\
\hline Large & $\begin{array}{c}4,561 \\
(69.4 \%)\end{array}$ & $\begin{array}{r}68,565 \\
(58.5 \%)\end{array}$ & $\begin{array}{c}1,145 \\
(17.4 \%)\end{array}$ & $\begin{array}{l}34,294 \\
(29.2 \%)\end{array}$ & $\begin{array}{c}865 \\
(13.2 \%)\end{array}$ & $\begin{array}{r}14,401 \\
(123 \%)\end{array}$ & $\begin{array}{c}1 \\
(0.02 \%)\end{array}$ & $\begin{array}{c}1 \\
(0 \%)\end{array}$ & $\begin{array}{c}4 \\
(0.1 \%)\end{array}$ & $\begin{array}{c}6 \\
(0 \%)\end{array}$ & 6,576 & 117,267 \\
\hline
\end{tabular}

Source: Ministry of Labor, Une mployment insurance DB, 2004. 
Table 4 further shows that the implementation ratio decreases significantly in relation to smaller company size. In small companies (less than 50 employees), only 10.3 percent of workers participated, whereas 52.4 percent of employees did so in large companies (140-299 employees) (Jang \& Yoo, 2006).

Table 4. e-Learning Program Proportion Change by Company Size in 2006

\begin{tabular}{|c|c|c|c|c|c|c|}
\hline \multicolumn{2}{|l|}{ Category } & \multicolumn{3}{|c|}{ Company Size } & \multirow[t]{2}{*}{ Total } & \multirow[t]{2}{*}{ Difference } \\
\hline & & $\begin{array}{c}\text { Less than } 50 \\
\text { Workers }\end{array}$ & $\begin{array}{c}50 \text { Workers to } \\
\text { Less than } 149 \\
\text { Workers }\end{array}$ & $\begin{array}{l}150 \text { Workers to } \\
\text { Less than } 299 \\
\text { Workers }\end{array}$ & & \\
\hline \multirow[t]{2}{*}{ e-Leaming Program } & Yes & $8(10.3)$ & $15(24.6)$ & $22(52.4)$ & $45(24.9)$ & \multirow{3}{*}{$\begin{array}{c}x^{2}=23.938 \\
p<01\end{array}$} \\
\hline & No & $70(89.7)$ & $46(75.4)$ & $20(47.6)$ & $136(75.10$ & \\
\hline \multicolumn{2}{|l|}{ total } & $78(100.0)$ & $61(100.0)$ & $42(100.0)$ & $181(100.0)$ & \\
\hline
\end{tabular}

Source: Jang, M. H., \& Yoo, S. J. (2006). E-Leaming Needs Analysis for the Employees of Medium and Small Companies.

Journal of Vocational Education \& Training, 9(3), 175-202.

At first glance, the Internet correspondence training system appears to provide broader access to educational opportunities in Korea. It seems to put training within reach of those employees who would not otherwise engage in such an opportunity. In reality, however, it fails to achieve that goal. Assembly line workers and those employed by small- or medium-sized companies have not received equal opportunities for the Internet correspondence training.

\section{Issues in Corporate e-Learning in Korea}

Although there have been great developments in corporate e-Learning in Korea over the past six years, there remain certain key problems in the field: moderate quality, uniformity and controlled growth, limited evaluation criteria, and unevenly distributed adoption rates.

\section{Moderate quality of corporate e-Learning}

The quality of corporate e-Learning has become an issue that has only been compounded by rapid growth. As mentioned, since the 1999 introduction of e-Learning in Korea two formats have emerged as preeminent: one is LOD (Lecture-on-demand) in which the presentation of a lecturer is recorded in motion picture, and the other is Web-based instruction in which text, graphic, and some animated objects are displayed on webpages as the learners click to progress. LOD has become a dominant format because not only it was easy and relatively inexpensive to develop, but it also conformed to expectations of what training should be (i.e., lecture delivery at learners' convenience). A small percentage of e-Learning was developed as Web-based instruction and most of this type were just copies of printed materials without learners' active participation. These problems were partially remedied when the new assessment system was introduced in 2001. As Table 5 illustrates, growth stalled in 2002 (the number of total institutes decreased from 110 to 93) with the introduction of governmental regulations, of which the assessment system was a key provision. The system succeeded in upgrading the quality of tutorial-type e-Learning programs at the expense of other formats. The quality issue will be discussed in more detail in the latter portion of the quality assurance section. 
Table 5. Number and Increasing rate of Corporate e-Learning Institutes in Korea (2001-2005)

\begin{tabular}{|c|c|c|c|c|c|c|}
\hline \multirow[t]{2}{*}{ Year } & \multicolumn{2}{|c|}{ Self-dev eloping } & \multicolumn{2}{|c|}{ Outsourcing } & \multicolumn{2}{|c|}{ Total } \\
\hline & Institutes & $\begin{array}{c}\text { Increasing } \\
\text { rate }\end{array}$ & Institutes & $\begin{array}{c}\text { Increasing } \\
\text { rate }\end{array}$ & Institutes & $\begin{array}{c}\text { Increasing } \\
\text { rate }\end{array}$ \\
\hline 2001 & 56 & - & 54 & - & 110 & - \\
\hline 2002 & 57 & $1.8 \%$ & 36 & $-50.0 \%$ & 93 & $-18.3 \%$ \\
\hline 2003 & 55 & $-3.6 \%$ & 33 & $-9.1 \%$ & 88 & $-5.7 \%$ \\
\hline 2004 & 53 & $-3.8 \%$ & 55 & $40.0 \%$ & 108 & $18.5 \%$ \\
\hline 2005 & 68 & $22.1 \%$ & 80 & $31.3 \%$ & 148 & $37.0 \%$ \\
\hline
\end{tabular}

\section{Uniformity and controlled growth}

The government initiative on corporate e-Learning in Korea has yielded unexpected results. Although it stimulated the quantitative increase of corporate e-Learning programs in a short period of time, one mode of e-Learning - the tutorial - dominated the e-Learning landscape. While the Evaluation System for Contents and Design Quality of e-Learning by the e-Learning Center (see Table 7) succeeded in upgrading the basic quality of the tutorials, it failed to encourage the development of diverse modes of e-Learning programs beyond simple tutorials, and also neglected to support new ideas and studies to help e-Learners become self-regulated or self-directed (Lim, 2005). Many e-Learners did not successfully complete the e-Learning programs in which they had enrolled; they dropped off early on or midway through because they were not self-motivated.

Although tutorial is an effective instructional type for certain objectives, it cannot support some essential objectives and activities, including teaching problem-solving skills, creative thinking skills, and self-directed learning. Yet these are the very skills and experience expected of workers in Korea's knowledge-based society. Corporate e-Learning in Korea, however, currently has not successfully promoted different e-Learning models such as Problem-Based Learning, Goal-Based Scenario, and Case-Based Learning (Kang, Kang, Song, Cho \& Lim, et al., 2006).

In addition, the government, by virtue of their initiative, regulated the growth of e-Learning in a way that stifled spontaneous innovation. Most companies assumed a passive role in designing and developing other types of e-Learning. The rapid growth of e-Learning was achieved without autonomous efforts from the corporate sector. For instance, the possibility of integrating eLearning with the knowledge management system in a company (Rosenberg, 2001) or with longterm blended learning strategies has not been systematically examined, in spite of the high demand.

On the other hand, some alternative designs have been explored from a theoretical standpoint. The Journal of Corporate Education in Korea has treated many topics related to course design, and secondly, to learner support and cost issues when those articles from the journal were analyzed by an analytical framework of Rha and Han (2002) (see Table 6). As this journal mainly focuses on the educational methods in corporate training, especially from the perspective of educational technology, this is not an unexpected result. The course design topics covered in the articles included 'strategies for learning motivation in e-Learning,' 'design strategies for goalbased scenarios,' 'blended learning strategies', and 'a design model for e-Learning.' On the other 
hand, as e-Learning is relatively new to adult workers, learner support issues have been widely discussed. The issue of cost has also been examined because the corporate sector has been particularly interested in determining whether e-Learning is cost-effective.

Table 6. The Topics of e-Learning Studies in Korea (1998-2006)

\begin{tabular}{lcc}
\hline \multicolumn{1}{c}{ Topics } & Frequency & Ratio \\
Course Design & 11 & $42.3 \%$ \\
Leamer support & 6 & $23.1 \%$ \\
Cost & 4 & $15.4 \%$ \\
Leamer participation & 3 & $11.5 \%$ \\
Leaming Contents & 1 & $3.8 \%$ \\
Other & 1 & $3.8 \%$ \\
Total & 26 & $100.0 \%$ \\
\hline from the Joumal of Corporat Education in Korea were selected for examination
\end{tabular}

In addition to the Journal of Corporate Education other academic journals and periodicals have also discussed topics related to e-Learning design. The Journal of Educational Technology in Korea, for example, has dealt with issues of corporate e-Learning from the perspective of educational technology, notably, issues such as tutoring (Cho \& Lee, 2004) and supporting selfregulation (Lim, 2005) have been areas of recent focus.

\section{Limited evaluation criteria}

It can be argued that the current perception of quality of corporate e-Learning can be attributed to the narrow and ambiguous evaluation criteria. Table 7 shows the current evaluation criteria for eLearning programs. It consists of five dimensions: instructional design, interaction, evaluation, instructional support design, and technology. Whereas the dimensions and the sub-criteria do cover important quality aspects of e-Learning programs, some problems still exist. First, they focus too narrowly on evaluating the tutorial type of e-Learning, virtually assuming that the tutorial format is the only one to assess; other types of e-Learning programs such as Case-Based Learning (CBL) or simulation have not been easily evaluated under these criteria. Second, they do not provide specific guidelines for each criterion. The criteria were ambiguous and judgment could vary depending on the evaluator. More specific guidelines in a rubric format should be developed to make the evaluation more objective and effective for future e-Learning programs. 
Table 7. The Evaluation Criteria for e-Learning Programs

\begin{tabular}{|c|c|}
\hline Dimensions & Criteria \\
\hline \multirow[t]{2}{*}{ Instruction Design } & Content presentation strategy and method relevancy \\
\hline & Suitability for supplementary \& advanced leaming resources \\
\hline \multirow[t]{4}{*}{ Interaction } & Appropriateness of leamer-instructor interaction \\
\hline & Appropriateness of leamer-leamer interaction \\
\hline & Appropriateness of leamer-contents interaction \\
\hline & Appropriateness of leamer-program manager interaction \\
\hline Evaluation & Appropriateness of method \\
\hline \multirow[t]{2}{*}{ Instructional Support Design } & Appropriateness of help function \\
\hline & Connectivity of navigation (Interface) \\
\hline Technology & Technical stability \\
\hline
\end{tabular}

Source: e-Leaming Center in KRIVET (2006)

\section{Unevenly distributed adoption rates}

As noted previously, the implementation of corporate e-Learning in Korea has mostly been confined to larger companies. Employees of small- and medium-sized companies have not yet fully experienced e-Learning programs. To overcome this shortfall, the Ministry of Labor's worker's tuition support system has been recently revised to provide financial support for these underserved workers (Lee, 2006). Further consideration in terms of more access to Internet correspondence training system is needed in order to improve corporate e-Learning in Korea.

From a theoretical vantage point, selected studies in the Journal of Vocational Education \& Training by KRIVET have discussed the issue of supporting medium and small companies, such as by beginning with an e-Learning needs analysis of these companies (Jang \& Yoo, 2006) and an assessment of e-Learning course selection criteria (Kwon, Lee, Rha, \& Lim., 2006). These studies were mainly conducted to come up with political implications for the future of e-Learning implementations at the national level. 


\section{Conclusions: Future directions and prospects}

The current development of corporate e-Learning in Korea was examined in terms of five aspects: 1) rapid quantitative growth, 2) government initiative, 3) dominance of the tutorial mode, 4) quality assurance, and 5) high adoption rate among large corporations. Each one of these also has a corresponding weakness. Rapid quantitative growth has meant that quality has at best been moderate. Government initiative has fueled complacency as companies have hesitated to develop their own e-Learning programs for specific purposes such as problem-solving or creative thinking skills. The dominance of the tutorial mode has kept other types of e-Learning from being actively designed and implemented. Quality assurance measures have used evaluation criteria so narrow and ambiguous that other types of e-Learning contents could not be easily evaluated and the evaluation was susceptible to subjective influence. And finally, the high adoption rate among large corporations has translated into workers of small and medium companies not having equal opportunities.

Nevertheless, corporate e-Learning does seem to have had a great impact on the recent development of life-long education and distance education in Korea. While the ratio of participants in life-long education in Korea has been relatively low among OECD countries (OECD, 2000), corporate e-Learning has played an important role in increasing the rate of participation rate in a short period of time. This increase was mainly due to the government initiative to transform the state into an information-based society where all the aspects of government, including education and training systems, rely on information infrastructure and environments. The Ministry of Labor was no exception, and it took advantage of the Employment Insurance Fund to achieve its goal for contributing to the information-based society. Companies were permitted to ask for government subsidy as long as they provided e-Learning programs for their employees. Implemented in 2000, this allowance had a significant effect on the growth of corporate e-Learning.

In this respect, corporate e-Learning in Korea is both unique and distinctive. The main impetus for its rapid growth has not been that companies needed to provide high-quality training programs to more workers, but that the government took initiative to transform the nation into an information-based society. Most e-Learning programs were tutorials that could be made easily, and their common objectives were for acquiring knowledge or understanding content (Lee, Byun, Kwon, \& Hwan, 2006). Companies wanted to ensure that employees could do their work competitively or show competency in new areas. They did not want any more workers who just understand basic, factual knowledge. Competency-related e-Learning or performance-based eLearning, however, has not been fully examined yet.

Corporate e-Learning can be improved in two ways. First, it should be dynamic rather than static, serving the new requirements of companies and employees. If it remains confined to traditional modes of education or schooling where understanding knowledge can be acceptable as an educational goal, it will be criticized and eventually phased out. It should be responsive to demands for new skills, competencies, or performance, training objectives that can improve employee effectiveness and efficiency. Therefore, the current government e-Learning initiative should be changed into one that is directed by both government and companies, one in which companies play an active, executive role and have a vested interest. Each company should be encouraged to develop and implement advanced and authentic programs autonomously, programs such as an e-Learning version of Problem-Based Learning or Case-Based Learning (Kang \& Oh, 2006). Evaluation criteria should also become more inclusive and go beyond examining the 
components of the tutorial; it should stimulate new trials and developments of corporate eLearning programs.

Second, corporate e-Learning is a kind of distance learning. Theoretically this provides more possibility to help adult learners access education and training opportunities. Corporate eLearning can provide training to employees who might otherwise never have had the opportunity to train because of time and space constraints. The initial implementation of corporate e-Learning was geared toward large corporations such as Samsung, LG, and SK. These corporations were relatively eager to adopt the program because they considered e-Learning to be cost-effective and to provide more training for their employees (Jang \& Yoo, 2006). Yet small- and mid-sized companies were not able to offer these programs due to financial constraints. Moreover, they did not recognize the value of e-Learning for their workers. To solve this inequality problem, the government should play a key role in encouraging the implementation of e-Learning. The Bureau of Small- and Mid-Sized Companies in the Ministry of Labor must come up with effective strategies to mitigate the imbalance, while the consortium of affected companies should take ownership of implementing e-Learning. In addition, government and companies should collaborate to provide leadership aimed at providing opportunities for the disadvantaged employees of these companies.

As mentioned, the unequal access to e-Learning should be acknowledged and countermeasures to provide more equal opportunities should be devised, especially for employees for whom eLearning is relatively new (Piskurich, 2003; Lim, 2005). Considering their schooling experience that focused on passive learning, it is easier to see how it may be difficult for such employees to manage their independent learning, or exercise appropriate self-direction or self-regulation (Lim, 2005 ) in learning. Providing facilitator intervention, or even a new learning management system to encourage and support learner's self-regulation systematically, are steps that could mitigate the problems. This issue in terms of supporting learner's self-direction or self-regulation should be studied and examined in further research.

\section{References}

Cho, E., \& Lee, S. (2004). Standardization factors in e-Learning environment for quality enhancement. Journal of Educational Technology, 20(2), 3-32.

Jang, M., \& Yoo, S. (2006). e-Learning needs analysis for the employees of medium and small companies. Journal of Vocational Education \& Training, 9(1), 175-202.

Kang, M., Kang, I. Song, S., Cho, I., Lim, C., Cho, S., \& Hur, H. (2006). Content design in eLearning. Seoul: Seohyunsa.

Kang, M., \& Oh, E. (2006). A survey on competencies of e-Learning designers in Korea. Journal of Vocational Education \& Training, 9(1), 203-230.

Kwon, S., Lee, S., Rha, H., \& Lim, Y. (2006). A study on the criteria and methods of selecting eLearning courses in corporate education. Journal of Vocational Education \& Training , $9(1), 231-250$. 
Lee, H. (2006). Promoting the knowledge-based economy through e-Learning. In Kim, J.(Ed.) New paradigms of human resources development. Seoul: Korea Research Institute for Vocational Education and Training (KRIVET).

Lee, S., Byun, S., Kwon, S., \& Hwan, H. (2006). Evaluation of internet correspondence training institutes, Year 2005. Seoul: Korea Research Institute for Vocational Education \& Training (KRIVET).

Lim, C. (2005). Development and effects of a Learning Management System for supporting selfregulated learning. Journal of Educational Technology, 21(4), 77-100.

Lim, C. (2003). Understanding distance education and cyber education. Seoul, Korea: Kyoyookbook.

Ministry of Commerce, Industry and Energy, Korea Institute for Electronic Commerce, \& Korea Association of Convergence Education. (2006). e-Learning White Paper 2005-2006. Seoul: Korea Association of Conversions Education (KAOCE).

OECD (2000). Literacy in the Information Age: Final report of the international adult literacy survey. Korea national statistical office.

Piskurich, G. M. (2003). Preparing Learners for e-LearnING. Danvers, CA.: Pfeiifer.

Rha, I., \& Han, A. (2002). A comparative analysis of students', instructors' and managers' perception on e-Learning. The Journal of Educational Information \& Media, 8(2), 115134.

Rosenberg, M. J. (2001). e-Learning: Strategies for delivering knowledge in the digital age. New York: McGraw-Hill.

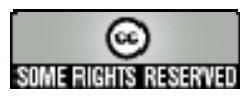

